\title{
LA POÉTICA DE LA TRANSCULTURACIÓN: ACERCAMIENTO A LA NARRATIVA DE MACEDONIO VILLAFÁN
}

\author{
Vidal Guerrero Tamara \\ Universidad Nacional Santiago Antúnez de Mayolo, Perú \\ vidalguerrerot@hotmail.com
}

\section{RESUMEN/ ABSTRACT}

A partir de las reflexiones de Ángel Rama en su texto fundacional La transculturación narrativa (1982), el presente artículo hace una revisión crítica de la narrativa del escritor peruano Macedonio Villafán Broncano. Enfatiza la construcción ficcional, las operaciones transculturadoras y los procesos complejos de resistencia cultural que experimentaron las sociedades andinas. Asimismo, articula con la epistemología andina y las dinámicas socioeconómicas como la reciprocidad, la complementariedad, la dualidad y la visión cósmica del hombre andino en plena modernidad. Con ello se evidencia que en la narrativa de Macedonio Villafán conviven dialécticamente una mezcla bicultural de los saberes ancestrales andinos y la cultura del invasor, constituyéndose en una muestra elocuente de literatura transcultural.

PALABRAS ClAVE: transculturación, Macedonio Villafán, andino, narrativa, epistemología andina.

\section{THE POETICS OF TRANSCULTURATION: APPROACHES TO THE NARRATIVE WORK OF MACEDONIO VILLAFÁN}

Based on the reflections of Ángel Rama in his foundational text La transculturación narrativa (1982), this article makes a critical revision of the narrative of the Peruvian writer Macedonio Villafán Broncano emphasizing the fictional construction, the transcultural operations and the complex processes of cultural resistance, experienced by Andean societies. It also establishes a link with Andean epistemology and socio-economic dynamics like reciprocity, complementarity, duality and cosmic vision of the Andean man within modernity. This shows that that in Macedonio Villafán narrative, a bicultural mixture of the ancestral Andean knowledge and the invading culture live dialectically together, constituting an eloquent example of transcultural literature.

KEYWORDS: Transculturation, Macedonio Villafán, Andean narrative, Andean epistemology.

Recepción: 23/03/2017

Aprobación: 28/06/2017 


\section{INTRODUCCIÓN}

Los estudios culturales latinoamericanos han tenido como punto de partida los aportes de Ángel Rama, cuya obra ha intentado construir una crítica literaria autónoma. Esta revela las múltiples dinámicas que han experimentado las sociedades latinoamericanas tan disímiles y contradictorias pero en ellas se encuentra el axis de su fertilidad. De entre las múltiples reflexiones que ha hecho Rama está su propuesta sobre la transculturación narrativa que procura interpretar, en terreno literario, esos procesos de fracturas sociales y culturales que han reorientado el destino de los pueblos. Las transmutaciones que se han operado al colisionar culturas foráneas con las culturas tradicionales, Fernando Ortiz las había llamado transculturación ${ }^{1}$. Término que luego sirvió de base para el sistema crítico que construyeron fundamentalmente Ángel Rama, Antonio Cornejo Polar, Néstor García Canclini o Walter Mignolo. Entonces, la genealogía de los estudios culturales se ha enriquecido desde los intentos por visibilizar los procesos coloniales hasta las complejas propuestas decoloniales que se han ido ensayando a partir de ejes sémicos como transculturación, heterogeneidad, mestizaje, sincretismo o hibridez.

En ese contexto, el presente artículo tiene el objetivo de centrarse en la propuesta de Ángel Rama en su texto corporativo ${ }^{2}$ La transculturación narrativa (2008 [1982]) que superando la antropología objetivista de Ortiz (1983 [1940]) coloca el neologismo en terreno literario. Su propósito fue dar cuenta de otros procesos que se venían produciendo en los medios subalternos, periféricos o en los espacios populares donde las culturas locales eran protagonistas de una desigual batalla por afirmar su identidad a partir de gestos transnacionales. Entonces Rama tiene el acierto de rescatar esas culturas de ese dispositivo de homogenización que aparentemente estaba

Fernando Ortiz (Contrapunteo 86-90) crea el neologismo transculturación que sustituye al término aculturación. El deslinde semántico y lingüístico lo hace en un contexto geopolítico, histórico, biológico, antropológico, económico e idiosincrático a partir de dos plantas que se transformaron en la base de la economía cubana: el tabaco y el azúcar. De manera que el término transculturación es empleado únicamente para describir el fenómeno social que vivía Cuba a partir del despliegue de su economía.

Uso el término corporativo para subrayar el carácter inorgánico del libro de Rama, toda vez que los capítulos insertos corresponden a trabajos independientes publicados en distintas fechas. De hecho, el primer artículo data de 1971 y se tituló "Los procesos de transculturación en la narrativa latinoamericana" (Sobrevilla 22). 
ganando terreno en las metrópolis y que marchaba victorioso para avasallar a las minorías que acaso son las mayorías; pero contra todo pronóstico, dejaban la impronta en cada acto, producto, signo o símbolo que ulteriormente se transformaría en materia prima de las diversas artes como la literatura.

Aunque las sociedades latinoamericanas a la fecha se han ido haciendo más complejas y la propuesta de Rama se constituya en procesual, nuestra pretensión es aplicar este concepto clave de la transculturación a la narrativa de Macedonio Villafán que representa aquella voz que Rodríguez llamaría sociedades marginadas (77). Por su parte, Lienhard propone identificar como literatura escrita alternativa (68-71), en tanto que Bendezú lo denomina "la otra literatura" (70-79), sin omitir la ya famosa metáfora de la latinoamericanización: "literaturas heterogéneas" de Cornejo Polar (Escribir 25-84). Suponemos que precisamente por el origen y la filiación de la obra de Villafán, la crítica especializada aún no ha mostrado su interés por estudiarlo. Para constatar esa esterilidad crítica haremos un breve mapeo sobre las opiniones y estudios en torno a su obra.

Posteriormente, la hipótesis central que demostraremos es que la poética de Villafán desde su ópera prima Los hijos de Hilario (1998) hasta la novela corta más reciente Cielo de las vertientes (2016 [2013]) desarrolla una lógica narrativa que contiene los tres elementos clave de las operaciones transculturadoras planteadas por Rama: el uso particular de los registros lingüísticos, la recuperación de la estructura literaria proveniente de la oralidad y la presencia de la cosmovisión andina. De este modo, el autor es un individuo que se identifica como mestizo, se transforma en una fuerza bifronte para visibilizar una cultura subalterna que ha sufrido distintos procesos culturales (partiendo de la aculturación). Villafán instrumentaliza estéticamente ese arduo sendero por el que transitaron los runas sin dejar de pensar y sentir en quechua.

\section{LA TRANSCULTURACIÓN NARRATIVA}

Fernando Ortiz desde un enfoque naturalista y etnográfico crea el neologismo "transculturación" en 1940. Este término, en su concepto, describe mejor los procesos sociales, económicos y culturales que vivían Cuba y el Caribe. Al respecto señala: 
Entendemos que el vocablo "transculturación" expresa mejor las diferentes fases del proceso transitivo de una cultura a otra, porque éste no consiste solamente en adquirir una distinta cultura, que es lo que en rigor indica la voz angloamericana "aculturation", sino que el proceso implica también necesariamente la pérdida o desarraigo de una cultura precedente, lo que pudiera decirse una parcial "desculturación", y además, significa la consiguiente creación de nuevos fenómenos culturales que pudieran denominarse "neoculturación" (90).

Ortiz postula esta visión antropológica cuando la sociedad cubana estaba experimentando, gracias al boom del azúcar y del tabaco, un despliegue económico importante que produjo la inmigración de diversos grupos étnicos como los chinos y los negros. Junto a los aborígenes no solo asimilaban la cultura del otro "civilizado", sino que en un proceso exocultural y endocultural se iban influyendo mutuamente. El resultado era una tercera cultura simbiótica donde el elemento autóctono se interpolaba con el elemento foráneo. Así enfatiza Mora cuando sostiene que "desde la perspectiva transculturalista, Ortiz posibilita integrar los fenómenos económicos, sociales, psicológicos y culturales. No únicamente se transculturaban los seres humanos, sino también las instituciones y los aspectos atinentes a la vida social” (75). Marrero precisa que Ortiz

[g]enera simultáneamente palabras para los conceptos implícitos: desculturación o exculturación, para la primera fase histórica de destrucción colonialista; inculturación como sustitutivo de aculturación para el fenómeno lineal de sumisión a la cultura de conquista; transculturación para la fase plena del proceso, esto es, para el intercambio en los dos sentidos; y neoculturación para la creación y definición de la cultura producto de todo el proceso (110).

A partir de estos procesos transitivos se plantean diversas metáforas latinoamericanas sobre sus dinámicas socioculturales que se hacen más complejas conforme se van produciendo contactos culturales que datan desde la invasión española ${ }^{3}$. Así, Ángel Rama rescata la voz “transculturación” de

\footnotetext{
Precisamos que los contactos culturales siempre fueron parte de la dialéctica del desarrollo de los grupos humanos. No olvidemos que las culturas azteca e inca, por ejemplo, se consolidaron como imperio a partir de invasiones sucesivas que permitieron la incorporación de grupos étnicos diversos en un solo estado, pero seguramente ninguno como la española que
} 
la hermenéutica ortiziana de las experiencias antropológicas, para aplicarla a las prácticas estéticas de las literaturas regionales y nacionales que no se reducen a las simples combinaciones de elementos diversos de frontera; sino que los sujetos que se encargan de la ficcionalización van diseminando un bosque de símbolos donde los aportes de la cultura europea sirven para los propósitos de los sujetos transculturadores.

En su momento, Rama recusó el concepto de transculturación que manejaba Ortiz con la aprobación de su maestro Bronislaw Malinowski, porque si bien en su interior consideraban diversos procesos culturales, sin embargo se asumía que los pueblos autóctonos solo servían de receptáculo y que casi no tenían la capacidad de influir. Frente a esto, Rama precisa que cuando el término se aplica a las obras literarias produce 1) una desculturación parcial que genera pérdidas de componentes obsoletos, 2) implica incorporaciones y 3) se da una recomposición de los elementos supervivientes de la cultura originaria y los que vienen de fuera. Observa que el término ortiziano no recoge los criterios de selectividad y los de invención que deben ser obligatorios en todos los casos de "plasticidad cultural" (45). Asimismo agrega que "la capacidad selectiva no solo se aplica a la cultura extranjera, sino principalmente a la propia, que es donde se producen destrucciones y pérdidas ingentes" (47).

No olvidemos que los elementos como la oralidad, la mitología, la cosmovisión o la riqueza cultural de los pueblos aborígenes pugnan, en el trabajo del transculturador, por ingresar a ese espacio de la tecnología que trajo el invasor: la escritura. En tal literaturización, queda el testimonio del campo de referencia externo que viven los runas: una negación de la desterritorialización de sus saberes y que las operaciones transculturadoras dan cuenta de las diversas posibilidades que han creado los pueblos para sobrevivir, porque "los caminos de la modernidad no son unilineales y no implican necesariamente la cancelación de matrices tradicionales" (GarcíaBedoya, Indagaciones 36).

Desde esa perspectiva se planteó, a partir de las lecturas de Rama, la necesidad de construir e instalar un discurso que vehiculice sus planteamientos, donde confluyan de manera inter y transcultural los procesos históricos indígenas, regionales, afrodescendientes, entre otras importantes comunidades históricamente desplazadas, y extraer de ellas la riqueza de sus culturas que

cometió en América, en pocos años, uno de los más espeluznantes genocidios que la historia guarde como testimonio (Todorov 144-157). 
nos permita construir el relato y la temporalidad nacional que incluya a todos los sectores y actores culturales. Esto permitiría, en lo que corresponde a la literatura, la formación de un proyecto de literatura latinoamericana (Benisz 39) enfocada desde una estrategia decolonial, aunque en ese proceso las sociedades, como parte de sus dinámicas, tengan diversas formaciones que dejan a las reflexiones de Rama como un punto de partida ${ }^{4}$.

En tal sentido, sus planteamientos deben ser juzgados a la luz de los procesos culturales. Rama, desde un racionalismo culturalista abogó por iluminar esa primigenia transmutación de las culturas. Tampoco es coherente que por estar atravesadas por modos de producción tradicionales y ser prácticas que el colonialismo juzga como primitivas o arcaicas, debían ser invisibilizadas. Si bien las sociedades latinoamericanas han seguido experimentando otras formas de contacto que deben ser leídas desde otras entradas como las enunciaciones heterogéneas, biculturales o bilingües, estas llevan en sus genes aquella tarea que Rama explicó para los transculturadores narrativos: aplicar "los procesos de selectividad y de invención en los casos de plasticidad cultural" (45) porque "la cultura europea coexistió y se superpuso en condición dominante a culturas locales vigorosas que conservaron en lo esencial sus matrices pre-coloniales" (García-Bedoya, Indagaciones 56).

En las dinámicas sociales, esta categoría de la transculturación le sirvió a Rama para aplicarla a esos procesos culturales de desterritorialización y reterritorialización a partir de la "otredad" de América y la riqueza de la civilización europea, que ha permitido finalmente que la confrontación cultural hasta nuestros días sea explicada, indudablemente, en términos de heterogeneidad o la llamada "totalidad conflictiva". Yangali subraya que:

Enfocarse en este tipo de literatura le permitió a Rama percibir que el regionalismo de los cincuenta distaba sobremanera del regionalismo indígena, del de la revolución o del de la tierra. (...). Se trataba de una narrativa regional que había superado los binarismos iniciales (localismo/cosmopolitismo, vanguardismo/regionalismo, tradición/

$4 \quad$ La evolución de las sociedades ha llevado a Trigo (147-148), Herrera (89) y Sobrevilla (23-24) a mostrar aporías aparentemente congénitas en la propuesta de Rama. Por su propia narrativa, los pueblos latinoamericanos, no son entes estáticos ni menos monológicos, pues en sus dinámicas reclaman los aportes interculturales para su desarrollo, por lo que necesitan nuevas metáforas culturales para entender sus procesos. Pero tampoco diremos como Moreiras (223) que la transculturación tuvo su final cuando Arguedas se suicidó. Postulamos que a partir de ese hecho, los sujetos transculturadores fueron más racionales en su trabajo estético. 
modernidad) no por rendirse a la modernización pasivamente sino al asimilarla para sus propios fines culturales. (22)

Pero pensamos que no solo la presencia o ausencia de la modernidad permitió avistar una especie de anquilosamiento en el desarrollo de una literatura transcultural latinoamericana, sino es necesario añadir también la indiferencia de los denominados novelistas telúricos por incorporar en sus creaciones los aportes vanguardistas que Europa estaba viviendo y que podrían haber mejorado la representación literaria de sus culturas. Desde la perspectiva colonial, los encuentros culturales se vuelven más trágicos cuando el sujeto colonizador emplea la fuerza para imponer su cultura; pero una adecuada lectura etnocultural basada en un imaginario etnocentrista que no se produjo, pudo haber encauzado oportunamente el desarrollo de la literatura latinoamericana desde los discursos de las regiones ${ }^{5}$. Consideramos el hecho de que Rama advierta que esta literatura sufrió un viraje cuando los escritores transculturales como Rulfo, Arguedas o Roa Bastos empiezan a introducir los recursos literarios vanguardistas en sus obras junto a la oralidad y la estrategia mítica como marcas de las sociedades periféricas.

Siguiendo a D'Allemand (141), planteamos que esta perspectiva transculturadora obliga a los académicos a hacer una relectura de la historia y la literatura latinoamericanas, a partir de las primeras obras de la literatura colonial que permitan el esclarecimiento de los procesos hegemónicos que se gestaron y cuáles fueron las múltiples maneras que emplearon los transculturadores para pasar de la oralidad viviente - en pleno proceso de desarrollo- a la escritura fría y perenne.

5 Esta afirmación se sustenta en la premisa de que los escritores regionalistas o indigenistas en Latinoamérica inicialmente partieron de una propuesta arcaica de escritura literaria, pese a que en Europa las vanguardias vivían sus horas liminares. Entonces queda interrogarse por las novelas Doña Bárbara (1929) de Gallegos, Huasipungo (1943) de Icaza o Yawar fiesta (1941) de José María Arguedas, cuyos logros estéticos son casi nulos si partimos de la noción de literatura transculturada. No olvidemos que por las fechas de publicación de esas obras ya se leían las novelas monumentales como Ulises (1922) de James Joyce o casi toda la narrativa de Kafka, y si nos atenemos a ejemplos en Latinoamérica consideramos a la lograda novela, para el contexto y la época, Don Segundo Sombra (1929) de Ricardo Güiraldes. 


\section{LECTURA DE LA CRÍTICA}

Entre los años de 1980 al 2000, el Perú vivió una guerra interna que según la Comisión de la Verdad y la Reconciliación (CVR) ocasionó cerca de setenta mil muertes y una pérdida millonaria ${ }^{6}$. Este hecho fue la piedra de toque para que cierto sector de la crítica especializada dirigiera su mirada hacia el interior del Perú. Aunque sus intereses se centraron en la denominada literatura de la violencia, permitió que algunos escritores como Óscar Colchado, Enrique Rosas Paravicino o Zein Zorrilla pudieran hacerse visibles en el contexto nacional e internacional. Sin embargo, una apreciable cantidad de escritores apenas están ingresando a las taxonomías o estadísticas pero sus aportes aún están en la sombra. Entre ellos cabe citar a Macedonio Villafán, cuya obra ya obtuvo lauros pero aún no ha logrado una presencia en los discursos de la crítica metropolitana. Entendemos que en esta situación se combinan distintos factores que tienen que ver con las agendas literarias, políticas, ideológicas, sociales y culturales que mantienen ocupados a los especialistas de la academia que en rigor continúan viendo de soslayo a las literaturas regionales. Precisamente por eso nos parece relevante hacer un breve balance de ciertas opiniones generales acerca de los aportes de Villafán en el panorama de la literatura peruana.

Gonzalo Espino (53-71) plantea la necesidad de elaborar una taxonomía que dé cuenta de la diversidad literaria en el Perú puesta de manifiesto de manera clamorosa cuando dos representantes - José María Arguedas a propósito de su centenario y Mario Vargas Llosa que recibió el Premio Nobel de literatura- llamaron la atención de la crítica internacional. Este hecho, para Espino, demuestra de manera fehaciente esa cartografía imprecisa de la narrativa peruana que no ha podido ser visibilizada. Cuando se refiere a Villafán, lo incluye en aquellos proyectos narrativos que están pendientes de atención por parte de la crítica especializada y lo anexa a José Oregón Morales, Cronwell Jara, Juan Rodríguez, Dimas Arrieta, Antonio Ureta y Ernesto Ramos que decidieron elegir como el lugar de la enunciación a las provincias. Asimismo, incluye la narrativa de Villafán dentro de la literatura

6 Comisión de la Verdad y la Reconciliación. Informe Final (Perú: 1980-2000). Lima, Universidad Nacional Mayor de San Marcos y Pontificia Universidad Católica del Perú. http:// www.cverdad.org.pe/ifinal/index.php. 
andina, constituyéndose en una práctica disidente, contrahegemónica o como decía Carlos García Miranda "anticanónica".

Posteriormente se ocupa de analizar algunos relatos de los libros Los hijos de Hilario y Apu Kolki Hirka, a quienes juzga como cuentos modernos enclavados en la tradición andina que guardan una relación directa con la oralidad y la memoria. Posteriormente destaca en todos la presencia del par dialéctico (modernidad del cuento y la memoria) como una operación semántica básica del pensamiento quechua. Luego, apoyándose en Elena Altuna, sostiene: "El soporte de la memoria no es gratuito porque el proyecto narrativo involucra lo que, en otra instancia, ha analizado Elena Altuna, una retórica del desagravio. Es decir, las opacidades o silencios de la historia oficial entran en clara tensión con las historias imaginadas y divulgadas por las colectividades indígenas (...)" (63). Destaca en Villafán la capacidad de descentrar el maniqueísmo indigenista e introducir el humor, el mito y ser un atento narrador que literaturiza los desplazamientos migratorios con asertividad. Luego focaliza su mirada en el relato "Réquiem por Miguel Broncano", del cual señala que parte de unos hechos históricos para arraigarse en los problemas identitarios. El cuento está concebido como una batalla por la voz y la representación simbólica. Sentencia que "se trata, entonces, de un relato de primer orden: la historia que se confronta con el documento desde la memoria" (68).

Bien, particularmente el par dialéctico que no termina aplicando al único cuento que comenta con profundidad nos parece muy artificial, forzado y que - la modernidad del cuento- no es parte de las dinámicas sociales quechuas. Quizá por la propia experiencia transcultural de los runas el par dialéctico tendría que haber sido planteado desde la dicotomía escritura/oralidad, que es donde, de manera elocuente, se presenta en el relato "Réquiem por Miguel Broncano". En él se establece un enfrentamiento con claras muestras de lograr una conciliación a medias. Finalmente (y paradójicamente), la exégesis de Espino asume implícitamente el par escritura/oralidad (al que llama guerra de cuentos) y termina contrastando esa dialéctica dejando a la modernidad soterrada del cuento.

En 2009 publiqué el artículo titulado "Lecturas sobre Los hijos de Hilario de Macedonio Villafán". El trabajo tuvo como basamento teórico los sistemas literarios desarrollados por Antonio Cornejo Polar ("Literatura peruana" y cf. García-Bedoya, Para una 54). De esta manera se procuró demostrar que el cuentario de Villafán no solo es expresión del sistema culto y popular sino que además reproduce esas voces subvertidas e invisibilizadas por la oficialidad a 
partir de dos ideas fuerza que impulsan la diégesis: los personajes subalternos y la evolución de las sociedades andinas. Se concluyó sosteniendo que "Los hijos de Hilario desborda los modelos primitivos de los códigos indigenistas, indianistas y ficcionales; para iniciar una senda promisoria en el panorama de las representaciones discursivas" (98).

Por otro lado, algunos estudiosos han destacado el trabajo de Macedonio Villafán a partir de la obtención del Premio de Literatura Quechua de la Universidad Nacional Federico Villarreal (1997). Entre ellos cabe citar a Miguel Gutiérrez (1999) y Ulises Zevallos Aguilar (Las provincias) ${ }^{7}$. En el caso del primero, destaca que la escritura en quechua de Villafán se produce en un contexto de renacimiento de una literatura en lengua quechua pero no desde la oralidad sino desde el ejercicio de la escritura. Esto obedece, según Gutiérrez, a la reconfiguración sociocultural que están viviendo las ciudades. Sin embargo muestra cierta incertidumbre sobre dos aspectos que enfatiza: acerca de los receptores de esa literatura y si el hecho de expresarse en lengua quechua puede garantizar la excelencia artística. Posteriormente señala que esas ficciones ya deberían de prescindir del realismo maravilloso y de los regionalismos lingüísticos para acercarse al uso de la lengua estándar que ponga fin a los últimos rezagos regionalistas. Gutiérrez apunta que las sociedades están cambiando, e insistir en los regionalismos es representar a sociedades arcaicas de manera extemporánea. Por otro lado, refiriéndose a la literatura quechua, señala que

(...) a través de esta literatura las poblaciones quechuas alcanzarían el derecho a ser escuchadas con su propia voz, si es que las producciones alcanzan un más que aceptable nivel artístico. Porque, en suma, son razones de orden estético las que confieren legitimidad a un texto narrativo, no el hecho más bien determinista de haber nacido su autor en el seno de una comunidad nativa (105-106).

Termina enfatizando que esta literatura tendrá futuro en la medida en que se integre a la literatura mundial y explore más en la condición humana prescindiendo de los temas locales (113-114).

7 Las tesis de Zevallos corresponden a su libro de 2009. Sin embargo, originalmente se publicó en 2008 en el formato de artículo académico en la revista Lhymen. Cultura y literatura 7, 5. Se han detectado mayormente variaciones a nivel formal. 
Las ideas que plantea Gutiérrez son sumamente reflexivas, pero su valoración es colonialista y chocanesca en el sentido que mira a las literaturas regionales con alma de conquistador y ojos de viajero. Esa lógica lo lleva a desmantelar a la novela Rosa Cuchillo de Óscar Colchado, calificándola como una suerte de cuento de hadas y poniendo en duda la pervivencia en la realidad fáctica de la visión cósmica andina que desarrolla la novela. Si Miguel Gutiérrez asume que la "quechualización" debe ser superada y que la visión mítica ya es extemporánea y no atiende a las representaciones actuales, entonces la base de la deconstrucción culturalista que ejecuta se erige sobre una concepción homogeneizadora y reduccionista. Finalmente es preciso puntualizar que el calificativo de "logro estético" no es un atributo de las literaturas escritas, porque las orales con sus propios códigos han demostrado alcanzar mayores niveles artísticos al ingresar a los procesos transculturales. Ejemplo de ello tenemos a tres novelas logradas: Rosa Cuchillo de Óscar Colchado, No preguntes quién ha muerto de Marcos Yauri Montero y Pedro Páramo del mexicano Juan Rulfo.

La mirada de Ulises Zevallos Aguilar (Las provincias 172-186) es opuesta a la lectura de Gutiérrez. Destaca el premio obtenido por Macedonio Villafán en el concurso promovido por la Universidad Nacional Federico Villarreal que se produce cuando los movimientos sociales, en general, han roto las fronteras nacionales y en ese espacio tenso renace la literatura quechua y se mueve en campos transnacionales. De ahí que elogia el logro de Villafán y lo coloca al lado de Dida Aguirre, Isaac Huamán, Fredy Amilcar, Odi Gonzáles, Anka Ninawaman, quienes desde su condición de sujetos biculturales están estableciendo diálogos entre culturas autóctonas y la cultura occidental. Asimismo, enfatiza que existe un renacimiento de la literatura quechua que se difunde en programas de radio en quechua, en ediciones bilingues y recitales en diversos departamentos del interior del Perú (170).

Sin embargo, Zevallos muestra su molestia por la ausencia de políticas de Estado que promuevan y difundan la literatura quechua. Le preocupa que las autoridades se mantengan indiferentes al vendaval neoliberal que intenta neutralizar y aniquilar estas prácticas. Culmina este tema señalando que, finalmente, es bueno que esas prácticas literarias aún se mantengan en las regiones, porque eso garantiza su pervivencia y asegura su desarrollo y diseminación por estar lejos de la vigilancia estatal y de las políticas poscoloniales. Por otro lado, en un artículo de 2014, Zevallos reafirma que la nueva narrativa quechua del Perú, a despecho de Mariátegui, Arguedas o Itier, no requiere necesariamente de una escritura en quechua porque este no 
es el único vehículo de comunicación. Es legítimo hacerlo en otras lenguas. Escritores como Conrad, Nabokov o Daniel Alarcón usaron otras lenguas para sus propósitos (241-242). Estas apreciaciones cancelan los prejuicios de Miguel Gutiérrez en el sentido de que la visión cósmica del hombre andino ya pertenece a la arqueología retórica ${ }^{8}$.

César Itier (1999 y 2015) plantea que Villafán, junto a escritores como Oregón Morales y Porfirio Meneses, ha creado textos literarios "absolutamente originales". Los considera pioneros en esta empresa que abre nuevos derroteros para la literatura quechua. Y augura que si esto continúa, el futuro del quechua está asegurado. Asimismo, cuando comenta el relato "Apu Kolki Hirka", desliza la idea de que el autor está fuertemente influenciado por la antropología moderna porque incluye voces e informaciones propias de su locus, además de que el registro lingüístico que usa es muy local y reclama la apertura de un horizonte lingüístico más amplio. Por otro lado, plantea que el cuento aboga por el retorno a la tradición desde una perspectiva indianista, que probablemente sea por la procedencia del autor de una zona donde la minería tuvo un impacto a nivel social y cultural.

En el rubro de las reseñas, Ulises Zevallos Aguilar (“Apu”) y Daniel Gonzales ("Villafán") hacen una valoración sobre los libros Apu Kolki Hirka y Los hijos de Hilario, respectivamente. En el caso de Zevallos, el relato quechua "Apu Kolki Hirka" lo coloca en el marco de los problemas que ha generado el despliegue de la minería en el Perú y señala que la profundidad de la lectura del relato dependerá mucho del tipo de recepción. Para ello precisa dos tipos de receptores: el lector occidental que probablemente entienda poco de la estrategia mítica que se plantea en el cuento, y el lector indígena o enterado de las culturas amerindias y por tanto competente para asimilar las vicisitudes que experimenta un $A p u$, dios montaña, en la cultura andina. Plantea que en la ontología quechua los dioses montañas ofrecen su riqueza en el marco de las relaciones de reciprocidad y complementariedad.

$8 \quad$ El hombre andino está tan vigente como su cultura. Prueba de ello es, solo en el caso de Huarás (Áncash), las celebraciones tradicionales como los carnavales donde las cruces milenarias se mezclan con las costumbres europeas; asimismo, la Semana Santa o la fiesta de mayo en honor al Señor de mayo que congrega a cientos de danzantes, bandas de músicos, mayordomos, etc. Incluso se han dedicado estudios regionales como el del escritor Marcos Yauri Montero (2013), que ha desarrollado la hipótesis de que el Señor de Mayo es una transmutación del otrora Dios prehispánico Guari que dominaba la zona del Callejón de Huaylas. 
Cuando el sujeto que explota sus riquezas se excede o es un extraño, entonces apela a distintas formas para esconder su riqueza y castigar a los intrusos y también a la población indígena. Termina su glosa sentenciando que el relato de Villafán se adelantó en veinte años "a los voceros de las teorías de desarrollo sostenible y cosmopolítica que tratan de hacer conocer la visión de los quechuas cuando sus tierras son privatizadas o concesionadas por sucesivos gobiernos que siguen políticas económicas neoliberales" (226) y añade que "Apu Kolki Hirka" registra un vaticinio sobre la catástrofe social y ecológica que han producido las empresas mineras.

Por su parte Gonzales señala que Macedonio Villafán "es un excelente creador de historias ambientadas en la zona sierra" (202), cuya obra muestra la vigencia de la narrativa provinciana en nuestra literatura peruana. Ya comentando el cuentario Los hijos de Hilario manifiesta que predomina el uso de la oralidad en un castellano quechuizado que le sirve al autor para metaforizar la cosmovisión andina propia del hombre de la sierra. Destaca la destreza narrativa del autor que explora las peripecias del hombre andino migrante y que ha accedido a la educación y se ha incorporado con éxito a las sociedades modernas. Gonzales ve en el primer cuento del libro, "Hilario Llanqui, mañana te fusilan", una loable combinación de datos históricos y contenidos míticos así como una técnica que aboga por el dato escondido. Por eso se pregunta: Hilario Llanqui, “ ¿fue fusilado realmente y su alma está integrándose al mundo de sus ancestros? $\mathrm{O}$ ¿en verdad se fugó para reunirse otra vez con las huestes de Uchcu Pedro?" (203). Sobre el relato "Cena de difuntos" señala la presencia de lo mágico como un letimotiv de casi todos los relatos. Este cuento que comenta está ambientado en el contexto de la guerra interna que asoló al Perú en los ochenta y noventa del siglo XX. El resto de relatos, Gonzales los reduce a una mera descripción de los contenidos. Culmina su reseña manifestando que el libro se diferencia de otros por el uso del lenguaje y la forma de ver el mundo.

Sánchez Garrafa destaca el conocimiento vivencial del mundo rural que tiene Macedonio Villafán, constituyéndose en un respaldo para sus creaciones literarias. Manifiesta que uno de los sustentos de su ficción es el empleo de la memoria individual y social. Luego del paratexto de rigor se ocupa en comprobar la presencia de la muerte en la narrativa de Villafán. Así, apelando a las citas textuales y a las glosas, señala que el tema de la muerte no es el único que amenaza a "la sociedad viva", sino que la emergencia de los espíritus penantes que habitan en el mundo subterráneo también dificultan la existencia. Ya comentando la novela corta Cielo de las vertientes manifiesta 
que pese a dominar el tema del amor en este texto "se estructura a partir del fallecimiento y entierro de la mujer amada, una flor de las vertientes, un fuego cuya impronta explica el presente y el tiempo vivido" (web). Sugiere que en el mundo andino la vida y la muerte son parte de la complementariedad y reciprocidad:

Pese al ser mestizo de los actores, a su condición económica y educación privilegiada, la subjetividad se alimenta aún de los ecos telúricos y de las voces de la tradición popular. Los hilos del destino son las coordenadas vitales de estos personajes más allá de los traslados espaciales y de la vorágine de los cambios en distintas épocas. La fuerza del amor conjuga pasión y una intersubjetividad cultural compartida que nos conmueve. No es la sociedad la que atenaza la existencia con sus tentáculos, es el sino, lo establecido que se plasma a despecho de cualquier circunstancia dejando lugar para una realización ideal del amor (web).

Hasta aquí los comentarios nos parecen muy sugerentes, sin embargo, la formación académica de Sánchez Garrafa y los textos sólidos que ha publicado no parecen haber influido en la elaboración de su artículo sobre Villafán. El tema de la muerte desde la perspectiva de la visión cósmica del hombre andino es complejo y está vinculado con la psicología, la antropología, las religiones, la arqueología y otros conocimientos más que Sánchez domina pero prefiere el comentario efectista y baladí. De ahí que su lectura termine constituyéndose en una suma de apreciaciones muy superficiales. Entendemos quizá que el nivel de su prosa atienda a los problemas de recepción en el medio que utiliza. Eso puede convertirlo inmune a la crítica.

Finalmente, consideramos necesario revisar los comentarios críticos de Alejandro Mautino, Mauro Mamani y Camilo Fernández, incluidos en el epílogo de Cielo de las vertientes (2016) ${ }^{9}$. Mamani considera que los personajes de Villafán, a diferencia de los de Colchado Lucio, hacen un recorrido transversal a los espacios educativos, es decir, de la escuela a la universidad

$9 \quad$ La primera y segunda edición de Cielo de las vertientes (Río Santa Editores, 2013 y 2014) lleva en el epílogo los comentarios de Mauro Mamani Macedo ("El arte de narrar el amor andino en Macedonio Villafán Broncano") y Alejandro Mautino Guillén ("Acerca de Cielo de las vertientes"). La tercera edición (Río Santa Editores, 2016) incorpora además de los trabajos citados, el comentario de Camilo Fernández Cozman ("La narrativa neoindigenista de Macedonio Villafán”). Las citas que se extraen pertenecen a esta tercera edición. 
y se desplazan desde su condición de alumnos a la condición de maestros, así como están asociados a los proyectos de modernidad como la educación y el Estado. Sobre Cielo de las vertientes señala que en la novela corta "el amor es pleno y honroso; es desplazado y aplazado, porque a pesar de las múltiples interferencias, se consuma con las últimas fuerzas escondidas en los rincones del cuerpo envejecido, que se aviva por el despertar del sentimiento" (81). Elogia la destreza de Villafán en el manejo de las tensiones y los artificios narrativos y enfatiza que solo un buen narrador es capaz de trenzar discursos.

Por su parte, Alejandro Mautino clasifica de manera implícita a Villafán en la corriente neoindigenista porque es "un actante que se moviliza, se transforma y rompe las antiguas relaciones de jerarquía, poder y subalternidad"(85) que exigía el indigenismo. Piensa que la metáfora del desplazamiento es la clave de la narrativa de Villafán porque el hombre andino ahora habita en una suerte de cosmopolitismo provinciano. Concluye sosteniendo que: "Cielo de las vertientes es un cuento donde la memoria convoca diversas etapas de la vida; diversas postergaciones de la libido en los amores adolescentes; reconstruye, a través de un personaje, la noción de sujeto plural de ciertas sociedades andinas que buscan desbordar lo geográfico y conectarse con la sociedad letrada provinciana" (90).

Camilo Fernández sostiene que Villafán es un escritor transcultural y destaca de Cielo de las vertientes la vinculación del nivel de la lengua con el nivel de la cosmovisión a través del plano de la estructuración literaria. Propone una intertextualidad con Los ríos profundos de Arguedas, por la condición de trashumancia de los personajes. Culmina su comentario señalando que el texto: “(...) es un cuento logrado, situado en el ámbito del neoindigenismo. Denota la fuerza poética del quechua que impregna el castellano como en esos relatos de Ciro Alegría y José María Arguedas donde la oralidad aparece, en un imponente concierto, en la escritura y teje recuerdos perdurables en la memoria" (93).

Es evidente que los tres comentarios intentan apreciar los aspectos estilísticos, formales, describir el contexto sociológico y literario en el que se desarrolla no solo Cielo de las vertientes, sino toda la narrativa de Villafán. La mayoría considera al autor como un atento transculturador que tiene la capacidad de interpretar las vicisitudes del hombre andino en contextos donde la modernidad predomina sobre las culturas locales. Sus miradas son reflexivas y parten de presupuestos teóricos que combinan exitosamente el impresionismo con los estudios literarios. 


\section{LA NARRATIVA TRANSCULTURAL DE VILLAFÁN BRONCANO}

Macedonio Villafán Broncano (Taricá, 1949) es de origen indígena, su lengua materna fue el quechua y su familia trabajó en las haciendas de la zona donde nació. Cursó la educación formal en la capital de la región Áncash, Huarás, luego estudió pedagogía en la Universidad Nacional de Trujillo. Hizo estudios de maestría y doctorado en la Universidad Nacional Mayor de San Marcos. Actualmente se desempeña como docente en la Universidad Nacional Santiago Antúnez de Mayolo de Huarás. Los textos narrativos que ha publicado son los cuentarios Los hijos de Hilario (1998), Apu Kolki hirka (1998), la novela corta Cielo de las vertientes (2013) y cuentos sueltos como "El enviado del dios Pachacámac" (2010), "Río Maranón, déjanos pasar" (2011), “Atahualpa, Pizarro e Inés Huaylas” (2009), "Los Barrón no se aburrían” (2009) y “Los Ariza" (2009). Sus trabajos han merecido reconocimientos como el tercer Premio COPÉ de cuento en 1987 y el primer puesto del Premio Nacional de Literatura Quechua de la Universidad Federico Villarreal en 1997.

Ahora se dirá en qué medida los datos biográficos se imbrican con el objetivo de este artículo, pues consideramos que los procesos de transculturación serán más visibles en la medida en que el sujeto transcultural conozca y distinga a posteriori la riqueza cultural autóctona a la que pertenece, y si por los intersticios se vislumbra una intención latente por visibilizar la guerra feroz y dialéctica que mantienen las dos culturas; entonces, la representación se constituirá en idónea y por tanto las operaciones transculturadoras permitirán desentrañar esa amplia gama de isotopías de las narrativas de la otredad. Finalmente, el punto de enunciación del sujeto bicultural y su historia constituyen dos aspectos que en los casos de Rulfo o Arguedas han permitido que la teoría ramiana pueda constituirse en un episteme clave en los estudios latinoamericanos. Así, la narrativa de Macedonio Villafán Broncano es heredera del indigenismo ${ }^{10}$ que llegó a su máxima cúspide con la obra de Ciro Alegría y José María Arguedas.

10 Tomás Escajadillo (27-102) ha planteado los diversos procesos que siguió el indigenismo desde aquel indianismo aún romántico y sin ánimos ideológicos hasta el neoindigenismo asociado con esas literaturas transculturales (103-241). En tanto que Cornejo ("Literatura" 12-27) postula que el indigenismo de los años 20 y 30 en el Perú se asoció a la lucha antioligárquica y estuvo marcada por una heterogeneidad sociocultural. Las prácticas indigenistas en la literatura destacan, según Cornejo, por la inclusión de canciones, los recursos paradigmáticos que niegan la secuencialidad de los sucesos y el fuerte sustrato mítico. 
Para desarrollar la afirmación precedente es necesario hacer un breve comentario sobre el espacio socioeconómico peruano. Según Nieto Degregori ("El debate" y "Los escritores"), esta narrativa de corte indigenista tuvo su apogeo hasta la primera mitad del siglo XX. Desde la perspectiva de los estudios sociológicos y antropológicos, los pueblos andinos que otrora habían tenido un enfrentamiento por la expropiación de sus tierras y contra el endurecimiento del gobierno central, ahora eran protagonistas de las grandes oleadas migratorias del campo hacia la ciudad. Este desplazamiento que conllevaría a una serie de secuelas de tipo socioeconómico y cultural traza el mapa de un nuevo rostro que Matos Mar (111-148) denomina desborde popular. El nuevo panorama social de la ciudad condensaba un crisol de culturas y saberes, ideologías, idiosincrasias, religiones, cosmovisiones que desde las lecturas de Matos Mar han producido la formación, por un lado, de un Perú oficial o formal a la manera de la ciudad letrada de Rama, y por el otro, un Perú marginado pero plural y multiforme (97-107).

Entonces, los escritores que continuaron la senda de los indigenistas asumían ahora nuevos compromisos desde sus espacios por traducir esa nueva realidad tan compleja, a veces ininteligible, pero donde la escritura ética se imponía por estar más cerca de los pueblos, o por ser precisamente descendiente de esas familias que migraron o sufrieron las consecuencias de la guerra que declararon al estado peruano tanto el Movimiento Revolucionario Túpac Amaru como Sendero Luminoso.

Este giro social, cultural, ideológico y hasta político tuvo una eclosión de escritores comprometidos con aquella escritura ética y que discrepaban del rótulo de neoindigenistas encajado por la crítica local. De manera que por la procedencia -mayoritariamente andina- o por los temas que exploraban la problemática de las regiones y los pueblos recónditos, fueron incluidos dentro de lo que hoy llama un sector de la crítica como literatura andina. Estas hipótesis son compartidas por distintos estudiosos como Terán (2005), Osorio (1995) y Cox (2005) ${ }^{11}$, que coinciden en incluir en esa tendencia a escritores como Óscar Colchado, Enrique Rosas, Zein Zorrila, Macedonio Villafán, Luis Nieto Degregori, Feliciano Padilla, Jorge Flores, Dante Castro,

11 Estos críticos caracterizan a la literatura andina, contextualizan y plantean algunas etapas de su desarrollo apelando a la dualidad literatura-sociedad. Sin embargo, los aportes rebasan los objetivos de este artículo pero quedan como lecturas abiertas para un estudio desde otras entradas. 
Mario Guevara, Jaime Pantigoso, Julián Pérez, Juan Alberto Osorio, Mario Malpartida, entre otros.

Particularmente, Macedonio Villafán ha desplegado un enorme trabajo por visibilizar al hombre del Callejón de Huaylas, las fracturas que ha vivido, los sueños y esperanzas que ha albergado, las derrotas y amarguras que ha experimentado. En su prosa lírica, a veces irónica, hace un uso efectivo de las estrategias narrativas siguiendo la senda de un verdadero transculturador narrativo. Su obra revela un desgarramiento cultural y una dramática búsqueda de la afirmación del sujeto escindido, primero como persona y luego como un ser que reconoce en la riqueza de su cultura la fuerza para luchar contra la homogenización. De hecho, Villafán es, desde la perspectiva de Noriega ${ }^{12}$ (Caminan 43-55) y Cornejo (Escribir, 1994 207-219), un sujeto migrante andino o un mestizo-quechua (Zevallos, Las provincias 170) que habiendo interactuado con las "bondades" de la cultura occidental vuelve a su terruño para librar la batalla desde la pluma. Nos muestra, a despecho de cierto sector de la crítica loadora de la postmodernidad, que la cultura autóctona está vigente. Su literatura es apenas un medio por donde desfilan las diversas maneras de resistencia cultural que vivieron los runas por siglos.

Villafán desde su primer libro se muestra muy atento a los cambios socioculturales que ha sufrido el hombre andino desde la llegada de los españoles hasta nuestros días (Robles 26-27), por eso se impone la tarea de cubrir en la ficción el recorrido histórico de los runas que llega a su cristalización con el libro Los hijos de Hilario (1998), donde se leen los avatares del hombre andino que abarcan aproximadamente una centuria (desde finales del siglo XIX hasta la segunda mitad del siglo XX).

De manera que el cuentario se divide en tres acontecimientos históricoliterarios muy marcados: el denominado indigenismo ortodoxo, los contactos culturales entre las culturas locales y la modernidad y, la denominada literatura andina. Esta estructura se condice con los procesos culturales: colonización, descolonización y recolonización, o lo que Rama (47) propone como pérdidas, selecciones y transformaciones. Así, el cuento "Hilario Llanqui mañana te fusilan" se ubica en el primer proceso donde los indígenas luchan por la

12 Julio Noriega con anterioridad (Escritores) postuló la hipótesis de que un sector de cultores de la poesía quechua en el Perú "son bilingües educados y migrantes andinos en la capital" (115), posteriormente valida su hipótesis cuando extiende esa nomenclatura para los narradores. 
reivindicación de sus derechos, mientras las fuerzas represivas del Estado aplacan la rebelión mediante la violencia. Predomina la oralidad y la estrategia mítica. El protagonista del relato, Hilario, asciende al Janan Patsa, el mundo de arriba, como premio a la práctica de la reciprocidad y la complementariedad. Queda en la retina del lector un latente discurso mítico-utópico del uno pachacuti, el mundo al revés. El fracaso de la rebelión indígena y el triunfo de las huestes del gobierno no se narran, pero queda en la prospección del lector; metaforiza el final de un ciclo y el avistamiento de otro. En suma, el hombre andino no claudicará en sus pretensiones porque ahora, bajo la forma de resistencia cultural, asimilará la cultura del otro a partir de una selección que posteriormente será leída como una estrategia de sincretismo.

La segunda fase está desarrollada en los cuentos "Tantas amarguras por ella" y "Fiesta grande" donde el sujeto andino asume la cultura del otro pero conservando la suya. Para lo cual primero se produce la diáspora quechua que enfrentan al hombre rural a una realidad nueva pero retadora para sus propósitos. En el primer relato se narra la migración y en el segundo, el retorno triunfante del sujeto andino que aprendió muy pronto que el dinero y la pomposidad, elementos clave del ascenso social, son garantías de éxito. Sin embargo, la fiesta que rinde honor a San Jerónimo condensa y formaliza la reciprocidad como el detonante de las actividades de todos los sujetos andinos que han logrado conciliar dos elementos culturales opuestos: el dinero y la religiosidad andina.

La tercera etapa está ficcionada en los relatos: "Cena de difuntos", "Sueños y viajes en las quebradas", "Como árbol sin frutos" y "Réquiem para Miguel Broncano". Cuentos que obedecen a un propósito explícito que el autor confesó a Ricardo Ayllón: "los elementos más importantes en mi trabajo actual son, primero, seguir las huellas del indígena ya modernizado, ello en cuanto a contenido, y segundo, seguir esforzándome artísticamente" (123-124). Desde esa perspectiva, el primer relato se sitúa en la guerra interna (1980-1992), el segundo demuestra que el capitalismo es finalmente un sistema económico y social excluyente e injusto, mientras que en los dos últimos relatos se desarrolla en su versión más dramática la dualidad: desterritorialización/reterritorialización. Por otro lado, en estos cuentos los registros lingüísticos muestran la dura batalla del encuentro de dos lenguas y su posterior resolución. Los sujeto andinos devienen en sujetos biculturales que viven bajo el influjo de la modernidad; pero que conservan sus prácticas culturales autóctonas como la presencia del famoso camaqen, la energía que anima la vida, identificada como el alma en la cultura occidental. Los dioses 
auxilian a los personajes en un discurso maravilloso. En un relato asombroso donde un nieto, luego de leer una leyenda antigua donde las almas se llevan a su abuelo, inicia un intraviaje para rehacer ese mundo mítico fabuloso a partir de la instrumentación de dos elementos de las culturas en conflicto: la escritura y la oralidad.

En el cuento "Réquiem para Miguel Broncano", el más logrado en nuestro concepto, se refiere la historia de un nieto de nombre Mashico, que intenta reconstruir la historia de su genealogía. Para ello examina documentos, interroga a testigos, recorre espacios que su abuelo Miguel Broncano transitó como arriero en la ruta de Huarás a Lima. Pero la complejidad reside en la recepción. Mashico, el personaje, a lo largo de su recorrido va abriendo heridas, diseminando incertidumbres, obteniendo pequeñas satisfacciones y muchas interrogantes donde los símbolos conviven con las grandes contradicciones. En suma, es un viaje para saber qué somos, por qué somos, cuál es nuestro rol en estos espacios y hacia dónde nos dirigimos. De ahí que este texto plantee una lectura simbólica de la resistencia de las culturas a la traducción y a la desterritorialización que se explica por los constantes silencios de los personajes (abuelo e hijos), la inmutabilidad de las cosas y las palabras escritas que convierten al narrador autodiegético en un sujeto marcado a fuego por la experiencia de la desterritorialización. Entonces, la construcción de su identidad se torna en un acto desgarrador donde, inexplicablemente, solo cuenta con una gama de signos donde reina la mayor tecnología occidental: la escritura. Finalmente, Villafán ha logrado, apelando al testimonio como género, construir una identidad ficcional que juega en la recepción con la dualidad verdad/ficción (Grillo 77) que implica la narrativización de lo factual apelando a los elementos suprafactuales.

En el libro Los hijos de Hilario coexisten diversos proyectos y subjetividades que demuestran cómo la transculturación ha permitido una solución a la problemática de los encuentros culturales, desplazándose exitosamente de la oralidad a la escritura, del mito a la modernidad, activando múltiples transculturaciones dado el estado dinámico de las sociedades. Por tanto, no podemos discutir los conceptos de mestizaje, hibridación o heterogeneidad si antes no hablamos de transculturación, porque en las tierras de América, el invasor tuvo un solo objetivo en relación con las culturas: liquidarlas. Por tanto todos los discursos que intentan explicar ese encuentro sangriento serán vulnerables si no parten del objetivo del colonizador y de los contrastes: individuo/comunidad, mito/historia, castellano/quechua, autoctonismo/ occidentalismo o sujeto migrante/sujeto mestizo. 
Para Lévi- Strauss, "el conjunto de los mitos de una población pertenece al orden del discurso. A menos que la población se extinga física o moralmente, este conjunto nunca se cierra" (17). Son producto del ejercicio intelectual libre de cualquier factor extrínseco a ella, por lo que su mente se muestra casi en su estado natural. Pero conforme los grupos humanos van creciendo, los mitos se van extendiendo y enriqueciendo por un proceso de transformación, sustitución, resignificación y sincretismo que finalmente es parte de sus dinámicas que les permite mantenerse siempre vivos. Los rasgos clave del mito son su carácter anónimo y la transmisión por la vía oral. Aunque su origen sea incierto, tiene la fuerza suficiente como para sobrevivir al tiempo e imponerse en la conciencia como una verdad conforme Edith Pérez reflexiona al respecto: "el mito expresa una forma de racionalidad. Es a través de este que el hombre puede conocer su realidad e interpretar el universo lleno de formas simbólicas; representando aquello que carece de especificación en el mundo de lo expresable" (80). En el mismo sentido, Rama añade que "el mito, en cuanto tal, es transparente a quien lo ejerce y jamás lo vive como una falsedad, del mismo modo que nadie vive su ideología como una falsa conciencia o una falsa racionalización, sino como una doctrina legítima fundada en valores objetivos" (Rama 330).

Por su parte Béjar (11 y 14) sostiene que los mitos fueron historias a menudo sagradas, narraciones de personajes y acontecimientos extraordinarios que dieron fuerza a las sociedades antiguas. Son orientadores de sueños, esperanzas, formas de vida y actitudes ante los sagrado y lo profano. Los mitos trascienden al tiempo, porque cada generación se encarga de diseminarlos, a veces para mantener un orden, $\mathrm{u}$ otras para crear otro orden o sencillamente cifrar en sus operaciones semánticas las claves de un pueblo que se niega a la extinción. Esto fue lo que sucedió por ejemplo con los mitos de resistencia cultural como el Taqui Onqoy, enfermedad de la danza (liderada por Juan Chocne que buscaba la restauración del culto tradicional), o el Muro Onqoy, enfermedad de la viruela. Ambos movimientos se constituyeron en expresiones de un sentimiento social de reivindicación y resistencia cultural.

Es por este sendero que transita el relato "Apu Kolki Hirka" (2014) de Villafán que logra sintetizar notablemente el mito con la historia, el tiempo cíclico andino con el tiempo cristiano, lo profano con lo sagrado, lo moderno con lo primitivo, el caos con el orden, el equilibrio con el desequilibrio y narrar desde el conflicto la guerra de cosmovisiones a pesar de la modernidad y el avance incontenible del capitalismo. El Apu Kolki Hirka, Dios montaña de plata ha permitido las sucesivas extracciones de plata de sus entrañas 
por siglos. A cambio ha esperado siempre la reciprocidad como principio de equilibrio cósmico. Pero con la invasión española en el siglo XVI se inició el saqueo y la sobreexplotación que no cesó hasta la segunda mitad del siglo XX. Aquí, el punto de enunciación, la voz autodiegética del Apu Kolki Hirka le confiere verosimilitud, subvierte el discurso y el texto termina convertido en un apólogo. Con este relato, Villafán, demuestra ser un sujeto transculturador ético e inteligente, que ha zanjado la tensión de los encuentros desde una "totalidad contradictoria" (Cornejo, "Literatura peruana"). El autor ha manipulado de manera artística lo mítico para adentrarse en lo mitológico y explorar las múltiples posibilidades de resignificar y resituar un mito sin perder la esencia que se transmite a través de la oralidad. Como dice Quezada:

Entonces, lo mitológico remite a lo que tiene significación solo para aquellos que lo estudian y lo cultivan; de algún modo, cabe decir que lo mitológico es algo hecho por los hombres que ya no viven el mito "desde dentro", que lo han objetivado (...). Hay, pues, en lo mítico, una racionalidad en tensión. Por contraste con lo mitológico, lo mítico hace sensible de golpe y para todos: algo es inmediatamente capaz de imponerse por la calidad de su presencia a la noción abstracta de una socialidad inherente al "vivir en grupo" (27).

Y este concepto de lo mitológico tiene su correlato con la hierofanía (Eliade 25) que los sujetos indígenas han construido en un no tiempo que es el tiempo esencial de los mitos milenarios. Propone en sus prácticas una unidad de subjetividades. Pero las invasiones y saqueos han confrontado también a nivel de los imaginarios una dualidad que casi arrasa con las formaciones cósmicas andinas: lo profano y lo sagrado. Por eso, el sujeto transculturador despliega en sus intencionalidades dos estrategias que cuestionan finalmente la imagen de nación construida por el sujeto colonizador: inscribir al mito como generador de sentidos en la vida del runa e interpelar a las políticas del Estado que promueven la destrucción del espacio sacro.

Si visualizamos las dos obras comentadas de Villafán se podrá inferir que la planificación narrativa parte de una identificación con la cultura de donde procede, que seguramente sea vano decirlo, pero que involucra a toda la instrumentación que pone en juego: técnicas narrativas, uso del lenguaje poético, estrategias míticas, voces polifónicas, carnavalización bajtiniana y recursos transculturales escrupulosamente seleccionados. Por eso, su compromiso y misión logran coronarse con la publicación del más reciente 
libro de amor andino: Cielo de las vertientes (2016). En él, el concepto de amor andino evoluciona desde una visión candorosa, luego erótica, más adelante como una experiencia espiritual, después sexual, hasta racionalizarse en la senectud. Para narrar este desplazamiento apela a los tiempos cíclicos del universo andino y a la fabulosa mitología (Huaris, Amarus, Pakarinas $\mathrm{y}$ dioses cósmicos quechuas) que se formalizan en la unión sexual de sus protagonistas (dualidad y complementariedad), además de servirse, como diestro transculturador que es, de tres recursos narratológicos claves: la analepsis, la prolepsis y los "tempos narrativos" (elipsis, sumario, escena, cámara lenta y pausa). Estos se encargan de sintetizar la dicha de amar y la desdicha de vivir por el alejamiento físico y espiritual del objeto de deseo.

Como vemos, el tema que elige el sujeto transculturador mestizo es el amor, que es inherente al ser humano al margen de la construcción cultural, pero los protagonistas y el escenario pertenecen a la geocultura andina. Entonces el discurso sobre el amor y las acciones que derivan de su activación ingresan a un sistema narrativo de frontera a la manera lotmaniana (26). La hegemonía del tema central -la historia de amor-gobierna el texto manteniendo eclipsada a la geocultura andina pero, por momentos, ésta la desborda y pone en jaque a la estructura en su totalidad (por ejemplo en las escenas de la fiesta patronal, las danzas típicas o en la huella de la diáspora quechua). Y esto es lo más significativo del libro desde la mirada ramiana. Pues Villafán, inteligentemente, ha usado un tema aparentemente central para realmente eclipsarlo en pro de las culturas tradicionales, porque como académico que es, sabe que la colonialidad ha reducido a simples gestos folcloristas a las tradiciones regionales y por eso usa las armas de narrador para mostrar su gran capacidad contestataria. Entonces la novela corta se bifurca y cede el paso a dos historias paralelas: una que sigue los vericuetos del amor y otra que reseña el universo andino con sus tradiciones y costumbres, sus danzas, la flora, la geografía, su gastronomía y la riqueza cultural latente en la vida de los runas. Así como la migración quechua transforma al sujeto indígena en un sujeto bicultural que accede a la universidad, termina sus estudios y vuelve a su terruño para desempeñarse como profesional. Al culminar la novela corta, este sendero de las culturas locales atenúa la aparente soledad cósmica al que estaría condenado el narrador tras la muerte de su amada. 


\section{CONCLUSIONES}

La literatura transcultural es una escritura que se funda a partir del drama personal de los sujetos transculturadores, conforme lo demostró Ángel Rama cuando estudió la obra de José María Arguedas. El drama se extendió, como es natural, a la batalla por crear un registro lingüístico que tradujera las culturas locales y se apropiara de los elementos foráneos. El resultado fue una articulación sincrética que generó un mestizaje cultural que tiene su isotopía en la heterogeneidad o la hibridación como parte de la dinámica de las sociedades.

En el caso de Macedonio Villafán Broncano, por su origen quechua y su historia personal, ha visibilizado con éxito la gran fecundidad de las sociedades quechuas, particularmente del habitante del Callejón de Huaylas, a partir de sus gestas, sus costumbres, sus bailes, sus tradiciones y su cosmovisión. Asimismo ha desarrollado los ideologemas del cosmopolitismo y de la narrativa mundial como son la identidad, la muerte (desde la concepción occidental) y la soledad existencial. Por eso, consideramos que Villafán es un transculturador nato que construye una identidad que refleja las culturas autóctonas, articulando sus objetivos hacia la negociación de las culturas, invocando al diálogo y a la inclusión como aspectos medulares para el desarrollo de una política intercultural.

\section{BIBLIOGRAFÍA}

Ayllón, Ricardo. Las preguntas del ornitorrinco. Diálogos con la literatura peruana. Lima: Ediciones OREM, 2010.

Béjar Rivera, Héctor. "Mito y utopía para entender al Perú”. Tesis doctoral. Universidad Nacional Mayor de San Marcos, 2011.

Bendezú, Edmundo. La otra literatura. México: Fondo de Cultura Económica, 1986.

Benisz, Carla. "Literatura paraguaya, transculturación y polémica: las formas de una "literatura ausente". Revista Chilena de Literatura 87 (2014): 23-46

Cornejo Polar, Antonio. "Literatura peruana: Totalidad Contradictoria". Revista de Crítica Literaria Latinoamericana 9, 18 (1983): 37-50.

Escribir en el aire. Ensayos sobre la heterogeneidad socio-cultural en las literaturas andinas. Lima: Editorial horizonte, 1994.

Literatura y sociedad en el Perú: la novela indigenista. Lima: Lasontay, s/a.

Cox, Mark. "La narrativa andina peruana”. Lhymen. Cultura y literatura 4, 3 (2005): 97-109. 
D’Allemand, Patricia. "Ángel Rama: el discurso de la transculturación”. Voz y escritura 6, 7 (1996): 140-167.

Eliade, Mircea. Tratado de historia de las religiones. Madrid: Ediciones Cristiandad, 1974.

Escajadillo, Tomás. La narrativa indigenista peruana. Lima: Amaru Ediciones, 1994.

Espino Relucé, Gonzalo. "Narrativas disidentes. Narrativas andinas del desagravio (Mario Malpartida, Nilo Tomaylla y Macedonio Villafán)". Moradas narrativas. Latinoamérica en el siglo $X X$. Aymará de Llano (ed.). Argentina: Universidad Nacional del Mar del Plata, (2012): 53-71

Fernández Cozman, Camilo. "La narrativa neoindigenista de Macedonio Villafán”, Cielo de las vertientes, Macedonio Villafán (epílogo). Chimbote: Río Santa Editores (2016): 91-93.

García-Bedoya, Carlos. Para una periodización de la literatura peruana. Lima: Latinoamericana editores, 1990.

Indagaciones heterogéneas. Estudios sobre literatura y cultura. Lima: Pakarina ediciones, 2012.

Gonzales Rosales, Daniel. "Villafán Broncano Macedonio. Los hijos de Hilario" Lhymen. Cultura y literatura VI, 4 (2007): 202-204.

Grillo, María Teresa. Discursos de la nación pendiente. Reflexiones sobre el testimonio de enunciación andina en el Perú. Lima: Pakarina Ediciones, Facultad de Letras y Ciencias Humanas-UNMSM, 2016.

Guerrero Tamara, Vidal. "Lecturas sobre los Hijos de Hilario de Macedonio Villafán". Sembrando Huellas. Revista Académico - Científica de Educación, Cultura y Sociedad en los Andes 1, 1 (2009): 87-99.

Gutiérrez, Miguel. Los Andes en la novela actual. Lima: San Marcos, 1999.

Herrera Pardo, Hugo. "De las "metáforas culturales" a la "metonimia discursiva" en la crítica latinoamericana. Alrededor del contrapunto entre "hibridez" de Néstor García Canclini y "sujeto migrante" de Antonio Cornejo Polar". Estudios filológicos 57 (2016): 79-101.

Itier, César. "El desarrollo actual de la literatura quechua." Amerindia 24 (1999): 40-45.

“Aqupampa, de Pablo Landeo Muñoz, la primera novela escrita en quechua". 2015. Web. 3 de marzo de 2017. https://hawansuyo.files.wordpress.com/2016/07/itieraqupampa-1.pdf(2016)

Lévi- Strauss, Claude. Mitológicas. Lo crudo y lo cocido. $6^{\text {a }}$ ed. reimpresión. México: Fondo de Cultura Económica, T. I, 2002.

Lienhard, Martín. La Voz y su Huella: Escritura y conflicto étnico-cultural en América Latina 1492-1988. $4^{\mathrm{a}}$ ed. México: Ediciones Casa Juan Pablos, Universidad de Ciencia y Artes de Chiapas, 2003.

Lotman, Yuri. La semiosfera I. Semiótica de la cultura y del texto.Trad. Desiderio Navarro. Madrid: Cátedra, 1996.

Mamani Macedo, Mauro. "El arte de narrar el amor andino en Macedonio Villafán Broncano", Cielo de las vertientes, Macedonio Villafán. (epílogo). Chimbote: Río Santa Editores, (2016): 79-84.

Marrero León, Erelis. "Transculturación y estudios culturales. Breve aproximación al pensamiento de Fernando Ortiz”. Tabula Rasa 19 (2013): 101-117. 
Matos Mar, José. Desborde popular y crisis de estado. Veinte años después. 1984. Lima: Fondo Editorial del Congreso del Perú, 2005.

Mautino Guillén, Alejandro. "Acerca de cielo de las vertientes", Cielo de las vertientes, Macedonio Villafán (epílogo). Chimbote: Río Santa Editores (2016): 85-90.

Mora Meza, Santiago. "El concepto de transculturación: un recorrido en la obra de Fernando Ortiz". Tesis de pregrado. Pontificia Universidad Javeriana, 2012.

Moreiras, Alberto. "José María Arguedas y el fin de la transculturación”. Ángel Rama y los estudios latinoamericanos. Ed. Mabel Moraña. Pittsburgh: Instituto Internacional de Literatura Iberoamericana (1997): 213-231.

Nieto Degregori, Luis. "El debate entre andinos y criollos en la narrativa peruana última", Márgenes 14, 17 (2000): 155-170.

"Los escritores andinos, la violencia y la invisibilidad". Revista Argumentos 4, 2008. Web. 23 de febrero de 2017. http://revistaargumentos.iep.org.pe/articulos/los-escritoresandinos-la-violencia-y-la-invisibilidad/

Noriega Bernuy, Julio. Escritura quechua en el Perú. Lima: Pakarina ediciones SAC, 2011. Caminan los apus. Escritura andina en la migración. Lima: Pakarina ediciones SAC, 2012.

Ortiz, Fernando, Contrapunteo cubano del tabaco y el azúcar. 1940. La Habana: Editorial de Ciencias Sociales, 1983.

Osorio, Juan Alberto. "La narrativa andina”. Sieteculebras 8 (1995): 9-10.

Pérez Orozco, Edith. Racionalidades en conflicto. Cosmovisión andina (y violencia politica) en Rosa Cuchillo de Óscar Colchado. Lima: Pakarina Ediciones y Facultad de Letras Ciencias Humanas de la UNMSM, 2011.

Quezada Machiavello, Óscar. "Del mito como forma simbólica a las estructuras y operaciones de sus semiosis". Tesis doctoral. Universidad Nacional Mayor de San Marcos, 2004.

Rama, Ángel. Transculturación narrativa en América Latina. 1982. 2ª ed. Buenos Aires: El Andariego, 2008.

Robles, Omar. Mishki Rimay. Lima: Ediciones Altazor, 2005.

Rodríguez, Claudia. "Las 'otras literaturas' de Latinoamérica. Criterios de inclusión y exclusión en el canon literario”. Documentos Lingüísticos y Literarios 28 (2005): 77-81.

Sánchez Garrafa, Rodolfo. "El tema de la muerte en los relatos de Macedonio Villafán Broncano". 2015. Web. 3 de marzo de 2017. markapacha.blogspot.com/2015_06_01_archive.html

Sobrevilla, David. “Transculturación y heterogeneidad: avatares de dos categorías literarias en américa latina". Revista de crítica literaria latinoamericana, 28, 54 (2001): 21-33.

Terán Morvelli, Jorge. "Grupos socio-culturales en la narrativa andina peruana contemporánea: del hermetismo resistente a la orgía universal". Lhymen, Cultura y literatura 4, 3 (2005): 111-136.

Todorov, Tzvetan. La conquista de América. El problema del otro. Buenos Aires: Siglo veintiuno editores, 2003. 
Trigo, Abril. "De la transculturación (a/en) lo trasnacional)". Ángel Rama y los estudios latinoamericanos. Ed. Mabel Moraña. Pittsburgh: Instituto Internacional de Literatura Iberoamericana, 1997. 147-172.

Villafán Broncano, Macedonio. Cielo de las vertientes [2013]. $3^{\mathrm{a}}$ ed. Chimbote: Río Santa Editores, 2016.

Apu Kolki Kirka. Dios Montaña de Plata. 1998. $2^{\text {a }}$ ed. Huaraz: Huaraz Fondo Editorial UNASAM, 2014. Los hijos de Hilario. Chimbote: Río Santa Editores, 1998.

Yangali Vargas, Jorge. "La representatividad de lo latinoamericano en la generación crítica (Homenaje a Ángel Rama)". Horizonte de la ciencia 4, 6 (2014): 19-23.

Yauri, Marcos. El Señor de la Soledad de Huarás. Discurso de la abundancia y de la carencia. Resistencia andina. 1993. $2^{\mathrm{a}}$ ed. Huarás: Killa Editorial - Fondo Editorial de la UNASAM-FCSEC, 2013.

Zevallos Aguilar, Ulises. "Gestión cultural en los Andes: Literatura quechua hoy”. Lhymen. Cultura y literatura VII, 5 (2008): 7-22.

Las provincias contraatacan. Regionalismo y anticentralismo en la literatura peruana del siglo XX. Lima: Ediciones del Vicerrectorado de la Universidad Nacional Mayor de San Marcos, 2009.

"Transformación de la nueva narrativa quechua del Perú contemporánea (20102014)". Revista canadiense de estudios hispánicos 39, 1 (2014): 239-256

“Apu Kolki Hirka, Dios montaña de Plata”. 2016. Diálogo 19, 1. Web. 24 de febrero de 2017: 225-226. Doi https://doi.org/10.1353/dlg.2016.0047 